\title{
Affordable Development and Qualification Strategy for Nuclear Thermal Propulsion
}

\author{
Harold P. Gerrish Jr \\ NASA Marshall Space Flight Center \\ Harold.P.Gerrish@nasa.gov \\ Samit K. Bhattacharyya, Ph.D., P.E. \\ President, RENMAR Enterprises, Inc \\ bhatt@,renmar.org
}

\begin{abstract}
Nuclear Thermal Propulsion (NTP) is a concept which uses a nuclear reactor to heat a propellant to high temperatures without combustion and can achieve significantly greater specific impulse than chemical engines. NTP has been considered many times for human and cargo missions beyond low earth orbit. A lot of development and technical maturation of NTP components took place during the Rover/NERVA program of the 60's and early 70's. Other NTP programs and studies followed attempting to further mature the NTP concept and identify a champion customer willing to devote the funds and support the development schedule to a demonstration mission. Budgetary constraints require the use of an affordable development and qualification strategy that takes into account all the previous work performed on NTP to construct an existing database, and include lessons learned and past guidelines followed.

Current guidelines and standards NASA uses for human rating chemical rocket engines is referenced. The long lead items for NTP development involve the fuel elements of the reactor and ground testing the engine system, subsystem, and components. Other considerations which greatly impact the development plans includes the National Space Policy, National Environmental Policy Act, Presidential Directive/National Security Council Memorandum \#25 (Scientific or Technological Experiments with Possible Large-Scale Adverse Environmental Effects and Launch of Nuclear Systems into Space), and Safeguards and Security. Ground testing will utilize non-nuclear test capabilities to help down select components and subsystems before testing in a nuclear environment to save time and cost. Existing test facilities with minor modifications will be considered to the maximum extent practical. New facilities will be designed to meet minimum requirements. Engine and test facility requirements are based on the driving mission requirements with added factors of safety for better assurance and reliability. Emphasis will be placed on small engines, since the smaller the NTP engine, the easier it is to transport, assemble/disassemble, and filter the exhaust during tests. A new ground test concept using underground bore holes (modeled after the underground nuclear test program) to filter the NTP engine exhaust is being considered. The NTP engine system design, development, test, and evaluation plan includes many engine components and subsystems, which are very similar to those used in chemical engines, and can be developed in conjunction with them Other less mature NTP engine components and subsystems (e.g., reactor) will be thoroughly analyzed and tested to acceptable levels recommended by the referenced standards and guidelines. The affordable development strategy also considers a prototype flight test, as a final step in the development process. Preliminary development schedule estimates show that an aggressive development schedule (without much margin) will be required to be flight ready for a 2033 human mission to Mars.
\end{abstract}

